\title{
Digital Fluency and Social Media Use: An Empirical Study of WeChat Use
}

\author{
Aoyan Liu \\ Harbin Institute of Technology \\ aoyanliu0403@163.com
}

\author{
Yan Li \\ Harbin Institute of Technology \\ yanlily.lihit@gmail.com
}

\author{
Hua (Jonathan) Ye \\ University of Auckland \\ jonathan.ye@auckland.ac.nz
}

\begin{abstract}
Social media has increasingly been used to deal with personal and professional issues. Past studies note that individuals of different digital fluency present distinct technology use behaviors. Yet, limited research has explored how digital fluency affects individuals' motivations and the use of social media tools. Based on uses and gratifications theory and digital fluency literature, we develop a model to explore the relationship between digital fluency and social media use. We tested our model by analyzing 262 responses from WeChat users. Results show that digital natives (individuals of high digital fluency) tend to use WeChat to broaden social network while digital immigrants (individuals of low digital fluency) tend to enjoy WeChat use and to use WeChat to maintain ties with friends and fulfill their information needs. Our findings contribute to the literature by identifying the theoretical and practical roles of digital fluency in social media use.
\end{abstract}

\section{Introduction}

As a dominant social media tool in China, WeChat has been providing various offerings [1]. Thanks to its easy-to-use and highly efficient functions, WeChat has a growing user base. A recent report shows that 768 million users $\log$ in WeChat every day and $50 \%$ of users use WeChat for 90 minutes per day [2]. Similar to Facebook messengers, WeChat supports real-time text, photo and voice messages, as well as voice and video call with others. WeChat also allows users to send location information, share moments, create personal official accounts and so on [3]. For individuals, WeChat helps build a strong sense of community and connection through social interactions, communication and cooperation [4]. For organizations, WeChat has become a tool for companies to maintain customer relationship and corporate images [5] by distributing designated information, commercial advertising and marketing campaigns. As a result, WeChat has become a necessity in Chinese daily life for both individuals and organizations.

Unlike other social media tools, the instant messaging of WeChat can increase connectivity and closeness of friendships among users [6]. Another unique feature of WeChat use is its "acquaintance" based relationship comparing to the open model used in other social media tools [7]. Thus, we believe research on WeChat will provide unique insights to both academics and businesses.

A recent industrial report notes that young users (aged 17-21) behave differently on WeChat from senior users (aged 55 or older) [2]. Specifically, it notes that young users are more active in WeChat Use in terms of messaging and posting moments. They tend to use text messages to contact others while senior users tend to send voice messages [2]. This report calls for more research on WeChat use patterns of different generations. Research on this topic can shed a light on how to help WeChat better cater to specific needs of different generations. Also, differing strategies for various generations can better engage WeChat users, increase its stickiness and enhance user loyalty [8].

Despite the use behavior patterns noted in the report, past literature on social media has been limited to focus on factors that affect social media use [9]. One stream of research has investigated the impacts of social media affordances, e.g., affordances of participation, interaction, engagement and connection [9]. Another stream of research has focused on examining whether demographics (e.g., gender, age, education, incomes) will matter in terms of social media use [10]. Limited research has delved into how individuals of various generations use social media.

Digital fluency can serve as a useful lens to study the question as it involves both age and accessibility to technology which can better explain the relationships between various factors and technology use intention [11]. Digital fluency refers to "the ability to reformulate knowledge and produce information to express oneself creatively and appropriately in a digital environment" [11]. Interestingly, previous 
research posited similar concepts, such as digital access, digital competence and IT literacy [12]. However, these concepts focus more on the accessibility to technology rather than the intentional use of technologies.

Past research on digital fluency suggests that people growing up in different digital environments tend to show distinct attitudes towards new technologies [13]. People who grow up with digital technologies are called digital natives and they present high acceptability and play with the new technologies [14]. Contrarily, people who contact with digital technology in their older age are digital immigrants and they find it difficult to keep up with modern technologies. Differences between digital natives and digital immigrants in terms of technology use have been conceptualized as digital fluency [11]. Digital fluency contains competencies and knowledge needed to participate in online contexts [15]. However, limited research has studied how individuals of various digital fluency use social media (WeChat in this study).

Thus, this study aims to answer our research question "How digital fluency can influence individuals' motivations and WeChat use?" WeChat use refers to the extent to which individuals will use WeChat to complete different tasks. To fill this research gap, we construct a model by theorizing the impacts of digital fluency on the relationships between user gratifications and WeChat use based on uses and gratifications theory (U\&G Theory). We derive independent variables from social (broadening social network and maintaining tie), hedonic (enjoyment), process (tension release) and content (information need fulfillment) aspects of user gratifications. To answer our research question, we explore the moderating effect of digital fluency on the relationships between user gratifications and WeChat use. We collect our data by sending questionnaires to WeChat users. In general, this paper contributes to the study of WeChat use by identifying the moderating effects of digital fluency on behavioral usage and guidelines for the practice.

\section{Literature review}

\subsection{Digital fluency}

Digital fluency is defined as the capacity to produce, reformulate knowledge and express oneself creatively and properly through digital information technology [11]. It is related to the knowledge, skills and attitudes required in using the technology for purposes in the digital age [11]. Specifically, extant research about digital fluency focuses on individuals' abilities of sourcing information, evaluating information quality and learning new technologies. In essence, digital fluency contains critical thinking, information grasping skills and specific knowledge usage. Demographic factors such as income, education, occupation, age, and gender are antecedents of digital fluency. Besides, organizational factors, psychological factors and social influences are also the antecedents of digital fluency [11].

Digital fluency also describes the interactions between individuals and technologies in general and is derived from the dichotomy, i.e., digital natives and digital immigrants [11]. Digital natives are generations of people who were born in digital age with good technology use ability and high self-efficacy. They are regarded as video gamers, technological literate, content creators, product rankers and multi-taskers which can bring learning and working expectations, propriety notions and continuous partial working attentions to both companies and society [16]. Digital natives tend to be more active online, e.g., learning by narrating their own experiences, innovating and strengthening social interactional connections, capturing and sharing useful information and creating a low-risk environment for communication [14]. Digital natives usually have a high digital fluency. Digital immigrants describe generations of people who are unfamiliar with information technologies and begin to use electronic products in their adult life [11]. As they use technology in later periods of their life, there exist a series of problems (e.g., resistance and anxiety towards technologies). They may not have corresponding mindsets and habits for the digital world. In particular, less participation and digital experience will increase psychological barriers that digital immigrants may encounter.

Research has focused on such digital statuses. Digital natives are used to receiving information quickly by processing and completing multiple tasks simultaneously because of higher competence with information technology [17]. With abundant knowledge and skills, digital natives are deemed to be highly motivated technology learners and users [18]. However, with limited digital competence, technology may be a mystery or a threat towards digital immigrants [18]. Nevertheless, some research holds a different view that digital natives are not necessarily digitally competent and factors such as personal experience and education can influence their technological competence $[19,20]$. To sum up, previous research has been limited to study the antecedents and consequences of digital fluency. This paper will explore how digital fluency affects individuals' motivation to use WeChat. 


\subsection{Uses and Gratifications Theory}

Uses and gratifications (U\&G) theory explores motivations of media use by achieving user gratifications [21]. This theory illustrates that users will present self-awareness and motivations when they adopt a new media [22]. This indicates that individuals are actively and consciously select the media to use. Social media provides access to various offerings, which satisfy individuals' diverse demands. Compared with other traditional models, U\&G theory emphasizes users' initiative and explains behavioral usage better by providing specific motivational information [23]. In addition, this theory highlights the impacts of social and psychological gratifications that shape people's motivation for using social media [24]. As per prior research, users can obtain various gratifications from using social media including content, social, process and hedonic gratification, which in turn drive their actual usage [25]. We use this theory to overarchingly guide the selection of independent variables.

Social gratification refers to satisfaction of social interaction arising from interactivity with other parties through usage of social media and maintaining mutual relationship with community members [26]. It is suggested that social media usage is motivated by socialization of "in-group" relationship building [27]. Thus, relationship building by maintaining ties with close friends and broadening social network lead to users' satisfaction with social networking [10]. Broadening social network belongs to a humanmessage interaction concerning users' interaction with news and messages [28]. Maintaining tie refers to social benefits individuals derive from establishing relationship and maintaining interpersonal interconnectivity with others in social networks [29]. For example, WeChat satisfies individuals' social connection needs through functions of Chats, Moments, Shake, People Nearby, and Message in a Bottle. Thus, in the context of WeChat, it provides an opportunity for users to connect and exchange with others through social interaction.

Hedonic gratification refers to hedonic expectation fulfillment containing entertainment, aesthetic enjoyment and hedonistic pleasure. It explains the degree to which social media is fun and entertaining to users. Hedonic value is positively related to users' attitudes and behaviors towards social media, which indicates that high level of pleasure and involvement lead to active attitudes of media users. According to $U \& G$ theory, enjoyment can be a major driver of social media usage. Enjoyment refers to the feelings that present the individual's pleasure when they use social information technology [30]. In general, WeChat users are able to gain enjoyment through functions of Games, My Posts, Sticker Gallery and Wallet.

Process gratification refers to satisfaction receiving from the process of searching for messages, passing time and self-expression [26]. Process gratifications are achieved from participating in the process of behaviors, rather than from message contents. Deriving from the extrinsic value of mediated messages, users can achieve process gratification by joining in usage process [26]. U\&G theory strengthens the impact of tension release on social media usage which refers to a kind of emotional vent and release including killing time, relieving boredom, forgetting problems, relaxing and escaping from reality [31]. In particular, Moments, Games, Top Stories and Mini Program functions of WeChat could assist to generate positive emotions.

Content gratification refers to information expectation fulfillment, such as information seeking and sharing [32]. If the information users received are better than expectation, they are more likely to achieve content gratification. As one kind of content gratification, information need fulfillment means individual's desire to pursue and gain information to meet their needs, including looking for information, finding relevant social events, pursuing new ways to do things and seeking what happens around [33]. To be specific, WeChat helps to satisfy content needs by applying functions of Group Chat, Top Stories, Moments and Official accounts.

\section{Research Model and Hypotheses}

\subsection{Digital Fluency}

For different digital groups, they present various WeChat use. First, groups with different digital status (e.g., digital natives vs. digital immigrants) have different learning abilities. Digital natives are usually believe to have high digital fluency [34] while digital immigrants to have low digital fluency. It is posited that digital natives have higher capacities and richer experiences of mastering modern technology, i.e., social media [18]. Second, these two groups show different requirements towards WeChat. Generally, digital natives are more willing to adopt WeChat and share information. This lies in the fact that new technology has become a part of their life. However, digital immigrants are less digitally competent which means that they must change their traditional behaviors when they try to adopt a new type of technology (e.g., WeChat). Thus, we put forward our hypothesis as follows. 
H1: Digital fluency is positively associated with individuals' WeChat use.

\subsection{Broadening Social Network}

Broadening social network influences WeChat use by enabling individuals to find contacts and connections with others through effective messages and information [10]. In other words, people turn to social media channels to look for useful information and gain messages in order to realize relationship maintenance through social enhancement [28]. According to $U \& G$ theory, individuals are goaldirected in choosing appropriate social media platforms.

As active media users, digital natives tend to use WeChat more frequently because of the social connection goal they pursue and gratifications they achieve from finding new contacts and keeping in touch with others through message sending and receiving [10]. However, keeping up with what is going on and expanding circle of acquaintances through WeChat are not attractive for digital immigrants. Instead, they prefer to get to know new people by conducting face-to-face talks and establishing trust first. Thus, we put forward our hypothesis as follows.

H2: Digital fluency positively moderates the relationship between broadening social network and WeChat use.

\subsection{Maintaining Tie}

Maintaining tie influences WeChat use by enabling individuals to integrate and interact with family, colleges and friends [35]. Interpersonal relationship encourages social media usage by developing interpersonal communications and building connections with others [35]. Social gratification gaining from strengthened social connectedness contributes to pervasive adoption of social media [35].

For digital natives, they tend to play with new technologies [36], e.g., social media, instead of using them to maintain relationships. They can develop closeness to people through various other channels, such as participating in social activities. Also, they tend to explore more relationships digitally. However, for digital immigrants, they catch up with old friends via digital channels. Therefore, they tend to communicate through WeChat which is popular and easy-to-use. Thus, we put forward our hypothesis as follows.

H3: Digital fluency negatively moderates the relationship between maintaining tie and WeChat use.

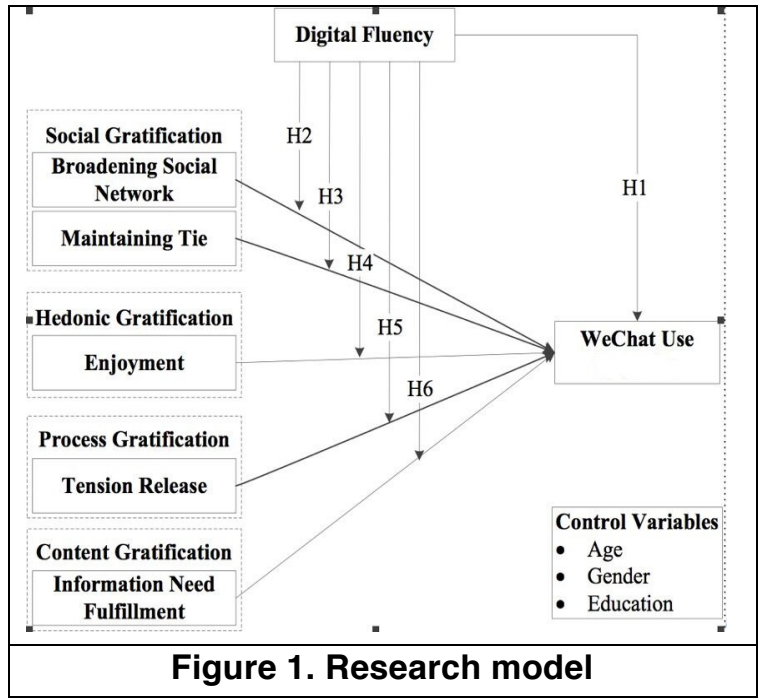

\subsection{Enjoyment}

Enjoyment influences WeChat use by enabling individuals to engage in activities of watching videos, playing online games with friends, paying attention to public account and skimming through updated posts of their contacts [37]. Enjoyment can increase users' hedonic gratification as social media is full of entertainment features.

Enjoyment meets digital natives' pleasant needs and increases their internal satisfaction towards WeChat. However, digital natives explore many technologies and the marginal utility from enjoying WeChat can be limited compared to digital immigrants who only experience a limited number of technologies. Digital immigrants are curious about various hedonic functions of WeChat, particularly Games and Moments, and are more likely to present increased use behaviors than digital natives. Thus, we put forward our hypothesis as follows.

H4: Digital fluency negatively moderates the relationship between enjoyment and WeChat use.

\subsection{Tension Release}

Tension release influences WeChat use by enabling individuals to kill spare time, relieve boredom and escape from reality [38]. Social media helps to relieve day-to-day stress and fulfill ritualized needs to overcome loneliness and forget about troubles [39].

Digital natives rely more on chatting on WeChat to escape from stress by losing track of time and forgetting about surroundings. However, as inactive WeChat users, digital immigrants may present passive attitudes towards tension release function due to less pressure they obtain from their daily life. Therefore, 
digital natives seem to be more sensitive to tension release function of WeChat than digital immigrants. Thus, we put forward our hypothesis as follows.

H5: Digital fluency positively moderates the relationship between tension release and WeChat use.

\subsection{Information Need Fulfillment}

\begin{tabular}{|c|c|c|}
\hline \multicolumn{3}{|c|}{ Table 1. Measurement } \\
\hline Constructs & & Items \\
\hline \multirow{4}{*}{$\begin{array}{l}\text { Digital } \\
\text { Fluency } \\
{[11]}\end{array}$} & DF1 & $\begin{array}{l}\text { I am able to quickly pick up new } \\
\text { features of WeChat }\end{array}$ \\
\hline & DF2 & $\begin{array}{l}\text { I am able to use WeChat moments } \\
\text { function to articulate my ideas }\end{array}$ \\
\hline & DF3 & $\begin{array}{l}\text { I often explore the new features of } \\
\text { WeChat }\end{array}$ \\
\hline & DF4 & $\begin{array}{l}\text { I am able to broadcast my ideas via } \\
\text { WeChat and other technologies }\end{array}$ \\
\hline \multirow{4}{*}{$\begin{array}{l}\text { Broadening } \\
\text { Social } \\
\text { Network } \\
{[10]}\end{array}$} & BSN1 & $\begin{array}{l}\text { WeChat helps me know more new } \\
\text { people }\end{array}$ \\
\hline & BSN2 & $\begin{array}{l}\text { WeChat helps me to expand my } \\
\text { circle of acquaintances }\end{array}$ \\
\hline & BSN3 & $\begin{array}{l}\text { WeChat helps me to contact with } \\
\text { new people different from myself }\end{array}$ \\
\hline & BSN4 & $\begin{array}{l}\text { WeChat helps me to undertake more } \\
\text { activities with other people }\end{array}$ \\
\hline \multirow{3}{*}{$\begin{array}{l}\text { Maintaining } \\
\text { Tie[10] }\end{array}$} & MT1 & $\begin{array}{l}\text { WeChat helps me to intensify my } \\
\text { connection to my close friends }\end{array}$ \\
\hline & MT2 & $\begin{array}{l}\text { WeChat helps me to constantly } \\
\text { contact with my close circle of } \\
\text { friends }\end{array}$ \\
\hline & MT3 & $\begin{array}{l}\text { WeChat helps me to maintain close } \\
\text { bond to friends I care about }\end{array}$ \\
\hline \multirow{4}{*}{$\begin{array}{l}\text { Enjoyment } \\
{[37]}\end{array}$} & ENJ1 & I find using WeChat to be enjoyable \\
\hline & ENJ2 & I feel good when using WeChat \\
\hline & ENJ3 & I have fun using WeChat \\
\hline & ENJ4 & I enjoy using WeChat \\
\hline \multirow{4}{*}{$\begin{array}{l}\text { Tension } \\
\text { Release } \\
{[40]}\end{array}$} & TR1 & $\begin{array}{l}\text { WeChat helps me to relieve } \\
\text { boredom }\end{array}$ \\
\hline & TR2 & $\begin{array}{l}\text { WeChat helps me to forget } \\
\text { problems }\end{array}$ \\
\hline & TR3 & WeChat enables me to relax \\
\hline & TR4 & WeChat helps me to kill time \\
\hline \multirow{4}{*}{$\begin{array}{l}\text { Information } \\
\text { Need } \\
\text { Fulfillment } \\
{[33]}\end{array}$} & INF1 & $\begin{array}{l}\text { WeChat can help me to acquire } \\
\text { necessary information }\end{array}$ \\
\hline & INF2 & $\begin{array}{l}\text { WeChat can help me to learn how to } \\
\text { do things }\end{array}$ \\
\hline & INF3 & $\begin{array}{l}\text { WeChat can help me to generate } \\
\text { ideas }\end{array}$ \\
\hline & INF4 & $\begin{array}{l}\text { WeChat can help me to get more } \\
\text { information for decision making }\end{array}$ \\
\hline \multirow{3}{*}{$\begin{array}{l}\text { WeChat Use } \\
{[10]}\end{array}$} & WU1 & $\begin{array}{l}\begin{array}{l}\text { I will still use WeChat in a frequent } \\
\text { way }\end{array} \\
\end{array}$ \\
\hline & WU2 & $\begin{array}{l}\text { In the next six months, I will still } \\
\text { frequently use WeChat }\end{array}$ \\
\hline & WU3 & $\begin{array}{l}\text { I will use WeChat instead of } \\
\text { discontinuing the use }\end{array}$ \\
\hline
\end{tabular}

Information need fulfillment influences WeChat use through information acquisition and information application aiming to generate ideas and make decisions [33]. Information need benefits can be grouped into general information networking benefits, social information on close friends and social information on broader network [10].

As digital natives are purposive to choose certain information to realize gratification, they tend to turn to WeChat to find necessary information about work, daily life, products, birthdays, deals and business details. Digital immigrants, however, may worry about information leakage, cheating and privacy concerns because of the functions of Card \& Offers, Card Repay, Mobile Top Up, Wealth, Utilities, QQ Coins and Public Services and other functions provided by thirdparty operator. Moreover, they have less information needs compared with digital natives. Thus, we put forward our hypothesis as follows.

H6: Digital fluency positively moderates the relationship between information need fulfillment and WeChat use.

\section{Research Methodology}

We collected online data by researching Chinese WeChat users. We did a pilot test first among ten random WeChat users of each age groups to pre-test the instruments and leave comments on length, wording and instruments which helped us to improve the quality of the final questionnaire and ensure the validity, reliability and clarity of it. Several ambiguous and unclear wordings and instructions of the items were modified according to feedback.

\subsection{Measurement Development}

Measurement items used in this study were adapted from related previous literature (see Table 1). Items were measured using a seven-point Likert scale ranging from 'strongly disagree' to 'strongly agree'. Items were translated into Chinese to reach a larger target population and avoid non-response problem. The process of developing these scales included a literature search, discussions with professors and postgraduates, a pilot test and data analysis. To tease out cofounding effects, age, gender, and education were included as control variables in our model.

\subsection{Data Collection}

We performed data cleaning by checking consistency after data collection, and finally we 
received 262 Chinese WeChat users' questionnaires from unbounded age groups with different education levels participated in this survey. Detailed information related to demographic characteristics of the sample is listed in Table 2. Results suggest that minors $(<18)$ and seniors $(>60)$ are more indifferent in WeChat usage than other age groups of people which is somewhat in line with previous study [41].

\begin{tabular}{|l|l|l|l|}
\hline \multicolumn{4}{|c|}{ Table 2. Demographic of respondents } \\
\hline Demographic Variables & Count & Percentage \\
\hline \multirow{4}{*}{ Gender } & Male & 124 & 47.3 \\
\cline { 2 - 4 } & Female & 138 & 52.7 \\
\hline \multirow{5}{*}{ Age } & $<18$ & 9 & 3.4 \\
\cline { 2 - 4 } & $18-25$ & 114 & 43.5 \\
\cline { 2 - 4 } & $26-30$ & 15 & 5.7 \\
\cline { 2 - 4 } & $31-40$ & 28 & 10.7 \\
\cline { 2 - 4 } & $41-50$ & 79 & 30.2 \\
\cline { 2 - 4 } & $51-60$ & 10 & 3.8 \\
\cline { 2 - 4 } & $>60$ & 7 & 2.7 \\
\hline \multirow{5}{*}{ Education } & High School & 67 & 25.6 \\
\cline { 2 - 4 } & Bachelor & 161 & 61.4 \\
\cline { 2 - 4 } & Master & 29 & 11.1 \\
\cline { 2 - 4 } & Doctorate & 5 & 1.9 \\
\hline
\end{tabular}

\section{Data Analysis and Results}

Partial Least Squares (PLS) was applied to analyze this research model and examine reliability and validity of the measures [42]. We used Smart PLS 3.0 software to conduct PLS analysis. We used partial least square structural equation modeling (PLS-SEM) rather than covariance based structural equation modeling (CB-SEM) for analysis because of its abilities to handle small sample size, complex models and non-normal data distribution. Consequently, PLSSEM is more suitable for our study in terms of the research objective, data characteristics and model setup. We conducted data analysis in two steps including assessing measurement validity and testing structural model.

\subsection{Measurement Validity}

We tested measurement validity by content validity and construct validity. We refined and modified items with high-degree validity and powerful explanations from previous literature to better reflect the context of our study. Moreover, item sorting was carried out by inviting people of five different aged to categorize the items into labeled and unlabeled groups. Result shows that the average accuracy of sorting reach $80 \%$ which presents good validity and reliability of this measurement.

\begin{tabular}{|l|l|l|l|l|l|l|l|}
\hline \multicolumn{7}{|c|}{ Table 3. Construct Reliability and } \\
Discriminant Validity \\
\hline & 1 & 2 & 3 & 4 & 5 & 6 & 7 \\
\hline 1.DF & $\mathbf{0 . 8 0}$ & & & & & & \\
\hline 2.ENJ & 0.62 & $\mathbf{0 . 9 1}$ & & & & & \\
\hline 3.INF & 0.43 & 0.53 & $\mathbf{0 . 8 7}$ & & & & \\
\hline 4.TR & 0.51 & 0.69 & 0.52 & $\mathbf{0 . 8 6}$ & & & \\
\hline 5.MT & 0.45 & 0.57 & 0.46 & 0.45 & $\mathbf{0 . 9 2}$ & & \\
\hline 6.WU & 0.44 & 0.51 & 0.27 & 0.28 & 0.51 & $\mathbf{0 . 8 8}$ & \\
\hline 7.BSN & 0.56 & 0.67 & 0.50 & 0.54 & 0.58 & 0.36 & $\mathbf{0 . 8 8}$ \\
\hline Mean & 5.17 & 4.77 & 5.62 & 5.07 & 4.84 & 4.51 & 5.14 \\
\hline SD & 1.36 & 1.72 & 1.45 & 1.51 & 1.65 & 1.58 & 1.14 \\
\hline Alpha & 0.80 & 0.93 & 0.89 & 0.89 & 0.90 & 0.85 & 0.91 \\
\hline CR & 0.87 & 0.95 & 0.93 & 0.92 & 0.94 & 0.91 & 0.93 \\
\hline AVE & 0.63 & 0.83 & 0.76 & 0.75 & 0.84 & 0.77 & 0.78 \\
\hline
\end{tabular}

Cronbach's Alpha, composite reliability (CR) and average variance extracted (AVE) were examined for convergent validity of the items. An Alpha reflecting internal consistency of constructs of greater than 0.7 , a CR of 0.7 or above and an AVE of greater than 0.5 are acceptance [43] which can be seen from details in Table 3. In addition, the factor loading of each item is required to be above 0.7 and actual loadings range from 0.70 to 0.95 which indicate that the constructs are assessed to be reliable [42]. Hence, all the values satisfy the criteria for convergent validity which means that the results are reliable and acceptable. Discriminant validity is the extent to which constructs that are not supposed to be related theoretically are unrelated in reality. If the square root of average variance extracted (AVE) for each construct is greater than correlation coefficient between a particular construct and any other construct, discriminant validity can be verified [44]. The AVE values in Table 3 meet this criterion, and therefore, the results suggest that the constructs are reliable and valid. On the other side, construct loading is another assessment factor of discriminant validity. All the indicators have higher loading values on corresponding constructs than other constructs. Due to the page limit, we have not included factor loading table. Furthermore, as can be seen from Table 4, all the HTMT values are less than 0.85 which means that discriminant validity has been established between given pairs of reflective constructs [45]. 
Consequently, the measurement model in this paper displays good reliability and validity.

\begin{tabular}{|c|c|c|c|c|c|c|c|}
\hline \multicolumn{1}{|c|}{ Table 4. Heterotrait-Monotrait Ratio (HTMT) } \\
\hline & DF & BSD & MT & ENJ & TR & INF & WU \\
\hline DF & 0.67 & & & & & & \\
\hline BSN & 0.18 & 0.20 & & & & & \\
\hline MT & 0.65 & 0.13 & 0.50 & & & & \\
\hline ENJ & 0.12 & 0.33 & 0.12 & 0.20 & & & \\
\hline TR & 0.62 & 0.27 & 0.27 & 0.19 & 0.08 & & \\
\hline INF & 0.57 & 0.24 & 0.51 & 0.13 & 0.12 & 0.05 & \\
\hline WU & 0.40 & 0.21 & 0.32 & 0.08 & 0.38 & 0.14 & 0.58 \\
\hline
\end{tabular}

\subsection{Structural Model}

Table 5 shows hypotheses testing results. The results indicate that the model explains $46 \%$ of the variances in WeChat use. In details, all the control variables are insignificant. All the cross-validated redundancy values $Q^{2}$ for each model are higher than zero, indicating that the model has predictive relevance to the DV. $f^{2}$ of 0.61 from Model 1 to Model 2 show a high effect size; however, $f^{2}$ of 0.19 from Model 2 to Model 3 presents a medium to large effect size. Also, GoF values are larger than 0.36, indicating a large and adequate goodness of fit [46].

We find that digital fluency has a positive impact on WeChat use (H1 supported). Also, we find that digital fluency positively moderates the relationship between broadening social network and WeChat use (H2 supported) while negatively moderates impacts of maintaining ties and enjoyment on WeChat use (H3 and H4 supported). However, we do not find a moderating effect of digital fluency on the impact of tension release on WeChat use. Surprisingly, we find a negative moderating effect of digital fluency on the impact of information need fulfilment on WeChat use.

\section{Discussion}

Results confirm that gratifications play important roles in determining whether to use WeChat especially in social gratification and hedonic gratification. However, our findings show that broadening social network and information need fulfillment do not exhibit any significant impacts on WeChat use which are in contrast with the results of previous study [33]. WeChat is a strong tie social network built on acquaintances. WeChat users aim to maintain the interactions with friends rather than getting new friends from online. Furthermore, obtaining information from such platforms present poor relationship. This could be due to the unique contextual features of WeChat, i.e., the acquaintance relationship. In nature, it may not be conducive to broaden social networking. Furthermore, in such relatively close-loop connection, i.e., strong ties, less new information will be shared than in an open social media vibe, e.g., Twitter and Facebook (i.e., weak ties).

Additionally, our findings show that digital fluency has no moderating effects on the relationship between tension release and WeChat use, meaning that it equally discourages both digital natives and digital immigrants to use WeChat for emotion release. This result is in contrast with previous outcomes as a large amount of studies hold that in terms of killing tiresome time and relieving boredom, most respondents employ Facebook to fill up spare or boring time at work or in class [38]. Further, when individuals are afraid of facing reality and they want to get away from current situation or play tricks on others, they tend to turn to SMS messages [39]. The possible reason of our result is that diluting negative moods has nothing to do with generations, and both digital natives and digital immigrants will find WeChat equally important in terms of dealing with stress.

In addition, the moderating effect of digital fluency on relationship between information need fulfillment and use behavior is negative, which indicates that informational functions of WeChat are less attractive for digital natives than digital immigrants. Digital natives may be more attractive to the open-model social media tools, such as Microblog. For example, Microblog assists young people in searching and gaining information about work, study and daily life which will in turn promote Microblog use behavior [25]. Information on close friends and social events support satisfaction with social networks and continuance intention among both young and old generation [10]. One probable reason of nonsupported hypothesis is that young people may concern about the accuracy of the information they obtain; thus, they may search information from more reliable channels. Another reason may be that sometimes the content of information derived from WeChat is redundant due to the acquaintance nature, which encourages digital natives to use other sources for new information.

\subsection{Theoretical Implications}

This study contributes to the literature in several ways which are discussed in further details below. First, this study extends social media literature by exploring the impacts of digital fluency [10, 47]. Specifically, we identified digital natives and digital immigrants as our two discussion groups. Taking the 
effects of digital fluency into account, our understanding of its role on WeChat use can be advanced because it helps to explore concrete behavioral usage differences among different digital groups. Our work fills in this gap by theoretically identifying the moderating variable (digital fluency) and empirically validating its effects. The importance of subdividing influencing factors of WeChat use lies in enriching contents of social media usage, expanding research scopes in IS field and providing basis for further exploration.

\begin{tabular}{|c|c|c|c|c|}
\hline $\mathbf{D V}=W \mathbf{W}$ & Model 1 & Model 2 & Model 3 & \\
\hline Age & 0.10 & 0.06 & 0.05 & NS \\
\hline Gender & -0.08 & -0.08 & -0.07 & NS \\
\hline Education & -0.05 & 0.05 & 0.05 & NS \\
\hline BSN & - & -0.10 & -0.06 & - \\
\hline MT & - & $0.33 * * *$ & $0.25 * * *$ & - \\
\hline ENJ & - & $0.41 * * *$ & $0.41 * * *$ & - \\
\hline TR & - & $-0.19^{*}$ & $-0.20^{* * *}$ & - \\
\hline INF & - & -0.04 & -0.02 & - \\
\hline DF & - & $0.20 * *$ & $0.18^{* *}$ & H1 V \\
\hline $\mathrm{DF} * \mathrm{BSN}$ & - & - & $0.16^{*}$ & $\mathrm{H} 2 \sqrt{ }$ \\
\hline $\mathrm{DF} * \mathrm{MT}$ & - & - & $-0.18 * *$ & H3 $\sqrt{ }$ \\
\hline $\mathrm{DF} * \mathrm{ENJ}$ & - & - & $-0.18^{*}$ & H4 V \\
\hline $\mathrm{DF} * \mathrm{TR}$ & - & - & 0.12 & NS \\
\hline DF * INF & - & - & $-0.11^{*}$ & NS \\
\hline $\mathrm{R}^{2}$ & 0.02 & 0.39 & 0.46 & - \\
\hline$f^{2}$ & & 0.61 & 0.19 & \\
\hline $\mathrm{Q}^{2}$ & 0.03 & 0.26 & 0.31 & \\
\hline GoF & & 0.58 & 0.64 & \\
\hline
\end{tabular}

Second, this study extends the social media literature by exploring use behaviors of a social network with strong ties. Previous social media studies examine users' behaviors in various types of social media platforms, such as Twitter, Facebook, LinkedIn and others [10], however, considering the special features of WeChat, our study will give a new insight to further understand the users' WeChat use in a strong tie network rather the general social network.

Third, the study adds to U\&G theory by introducing the impacts of digital fluency. Our findings add to $U \& G$ theory [21] by identifying the satisfactions of different gratification are dependent on digital fluency. It integrates four kinds of gratifications (social gratification, hedonic gratification, process gratification and content gratification) with digital fluency. Our findings confirm the effects of digital fluency and its moderating effects on shaping WeChat use, providing evidence support from theoretical perspective to the application of U\&G theory and the development of research model. This will give contributions to understand how technology use intention are effected by the related technology status. In summary, the creative combination of digital fluency and user gratifications provide clearer explanations of different WeChat use.

\subsection{Practical Implications}

Findings of this study also provide some implications for practitioners. Our findings indicate that old users tend to use WeChat to maintain the relationship with others rather than to obtain information and entertainment. This provides suggestions to WeChat designers that they should design functions according to their digital status.

Furthermore, this phenomenon is more significant among digital natives. Thus, for WeChat designers, the focus they should pay more attention is to strength the advantages, such as add new functions to increase the interactions between friends and design filter mechanism to divide friends with strangers.

Additionally, because users are not try to obtain information from such platforms, increasing highly relevant user generated content will increase their satisfaction, such as design classifications of posts or other personalized functions.

\subsection{Limitations and Future Directions}

This study exhibits several limitations that must be recognized. First, as we used cross-sectional data, longitudinal data should be collected to test whether the results hold. Second, digital natives will grow up as time goes by and the number of them will increase, however, the number of digital immigrants will decrease, therefore, our research has time limit which may be invalid many years later. Finally, as this paper only explores social media use in the context of WeChat (A typical type of social media). To generalize our findings, it is necessary to compare it with other social media tools widely used in terms of motivations and usage patterns.

\section{Conclusion}

This study has investigated digital fluency's influence on WeChat use. Results show that digital fluency affects WeChat use. Results also emphasize moderating effects of digital fluency on broadening social network, maintaining tie, enjoyment, and 
information need fulfillment. Findings from a large number of survey data can help businesses to market effectively and better serve existing and potential users. As a whole, this study is in line with the tendency and our findings enrich the understanding of social media use across different generations. Researchers and practitioners can benefit from knowing which needs and gratifications of different digital fluency to focus on as they explore extensive use of WeChat in future. Overall, we believe that our study contributes to future research in IS field.

\section{References}

[1] C. Zhang, Y.-N. Li, B. Wu, and D. Li, "How WeChat can Retain Users: Roles of Network Externalities, Social Interaction Ties, and Perceived Values in Building Continuance Intention," Computers in Human Behavior, vol. 69, pp. 284-293, 2017.

[2] WeChat. (2017). 2016 WeChat Data Report. Available: http://blog.wechat.com/2016/12/29/the-2016-wechat-datareport/

[3] H. L. C. a. Y. Cao, "Examining WeChat Users' Motivations, Trust, Attitudes, and Positive Word-of-Mouth: Evidence from China," Computers in Human Behavior, vol. 41, pp. 104-111, 2014.

[4] J. Qiu et al., "The Lifecycle and Cascade of WeChat Social Messaging Groups," pp. 311-320, 2016.

[5] M. Merolli, K. Gray, and F. Martin-Sanchez, Health outcomes and related effects of using social media in chronic disease management. Elsevier Science, 2013, pp. 957-969.

[6] W. Gao, Y. Liu, and L. Qian, "The personal touch of business relationship: A study of the determinants and impact of business friendship," Asia Pacific Journal of Management, vol. 33, no. 2, pp. 469-498, 2016.

[7] C. Mao, "Friends and Relaxation: Key Factors of Undergraduate Students' WeChat Using," Creative Education, vol. 5, no. 636-640, 2014.

[8] R. S. M. A. Hodis, and H. C. Sashittal, , "Interact with Me on My Terms: A Four Segment Facebook Engagement Framework for Marketers," Journal of Marketing Management, vol. 31, pp. 1255-1284, 2015.

[9] P. M. Leonardi and S. R. Meyer, "Social Media as Social Lubricant: How Ambient Awareness Eases Knowledge Transfer," American Behavioral Scientist, vol. 59, no. 1, pp. 10-34, 2015.

[10] H. Krasnova, N. F. Veltri, N. Eling, and P. Buxmann, "Why men and women continue to use social networking sites: The role of gender differences," Journal of Strategic Information Systems, 2017.
[11] Q. Wang, M. D. Myers, and D. Sundaram, "Digital Natives and Digital Immigrants Towards a Model of Digital Fluency," (in English), Business \& Information Systems Engineering, vol. 5, no. 6, pp. 409-419, Dec 2013.

[12] K. J. Fietkiewicz, E. Lins, K. S. Baran, and W. G. Stock, "Inter-Generational Comparison of Social Media Use: Investigating the Online Behavior of Different Generational Cohorts," pp. 3829-3838, 2016.

[13] V. L. C. D. L. Williams, T. Keo, and P. Mccarty,, "The Use of Social Media: An Exploratory Study of Usage among Digital Natives," Journal of Public Affairs, vol. 12, pp. 127136, 2012.

[14] J. Lei, "Digital Natives as Preservice Teacher," Journal of Computing in Teacher Education, vol. 25, pp. 87-97, 2009.

[15] C. Miller and J. Bartlett, "Digital Fluency: Towards Young People's Critical Use of the Internet," Journal of Information Literacy, vol. 6, no. 2, pp. 35-55, 2012.

[16] L. Rainie, "Digital natives invade the workplace," Pew Internet \& American Life Project, vol. 28, 2006.

[17] M. Prensky, "Digital Natives, Digital Immigrants Part 1," On The Horizon, vol. 9, no. 5, pp. 1-6, 2001.

[18] S. Bennett and K. Maton, "Beyond the 'digital natives' debate: Towards a more nuanced understanding of students' technology experiences," Journal of Computer Assisted Learning, vol. 26, no. 5, pp. 321-331, 2010.

[19] Y. Li and M. Ranieri, "Are 'digital natives' really digitally competent?-A study on Chinese teenagers," British Journal of Educational Technology, vol. 41, no. 6, pp. 1029-1042, 2010.

[20] R. X. Guo, T. Dobson, and S. Petrina, "Digital Natives, Digital Immigrants: An Analysis of Age and ICT Competency in Teacher Education," Journal of Educational Computing Research, vol. 38, no. 3, pp. 235-254, 2008.

[21] J. G. Blumler and E. Katz, "The Uses of Mass Communications: Current Perspectives on Gratifications Research. Sage Annual Reviews of Communication Research Volume III," 1974.

[22] R. W. Lariscy, S. F. Tinkham, and K. D. Sweetser, "Kids These Days: Examining Differences in Political Uses and Gratifications, Internet Political Participation, Political Information Efficacy, and Cynicism on the Basis of Age," American Behavioral Scientist, vol. 55, no. 6, pp. 749-764, 2011.

[23] M. M. Lambrechts, P. Perret, and J. Blondel, "Webbased information service adoption: A comparison of the motivational model and the uses and gratifications theory," Decision Support Systems, vol. 51, no. 1, pp. 21-30, 2011. 
[24] A. M. Rubin, "Media uses and effects: A uses-andgratifications perspective," Media Effects Advances in Theory \& Research, pp. 417-436, 1994.

[25] C. Gan and W. Wang, "Uses and gratifications of social media: a comparison of microblog and WeChat," Journal of Systems and Information Technology, vol. 17, no. 4, pp. 351363, 2015.

[26] I. L. B. Liu, C. M. K. Cheung, and M. K. O. Lee, "Understanding Twitter Usage: What Drive People Continue to Tweet," 2010.

[27] C. Peters, C. H. Amato, and C. R. Hollenbeck, "An Exploratory Investigation of Consumers' Perceptions of Wireless Advertising," Journal of Advertising, vol. 36, no. 4, pp. 129-145, 2007.

[28] H. Ko and M. S. Roberts, "Internet Uses and Gratifications: A Structural Equation Model of Interactive Advertising," Journal of Advertising, vol. 34, no. 2, pp. 5770, 2005.

[29] C. M. Cheung, P.-Y. Chiu, and M. K. Lee, "Online social networks: Why do students use facebook?," Computers in Human Behavior, vol. 27, no. 4, pp. 1337-1343, 2011.

[30] R. Tamborini, M. Grizzard, N. D. Bowman, L. Reinecke, R. J. Lewis, and A. Eden, "Media Enjoyment as Need Satisfaction: The Contribution of Hedonic and Nonhedonic Needs," Journal of Communication, vol. 61, no. 6, pp. 1025 1042, 2011.

[31] C. A. Lin, "Online-service adoption likelihood," Journal of Advertising Research, vol. 39, no. 2, pp. 79-89, 1999.

[32] H. Heijden, "User acceptance of hedonic information systems," Mis Quarterly, vol. 28, no. 4, pp. 695-704, 2004.

[33] H. J. Ye, Y. Feng, and B. C. F. Choi, "Understanding knowledge contribution in online knowledge communities: A model of community support and forum leader support," Electronic Commerce Research \& Applications, vol. 14, no. 1, pp. 34-45, 2015.

[34] C. Brown and L. Czerniewicz, "Debunking the 'digital native': beyond digital apartheid, towards digital democracy," Journal of Computer Assisted Learning, vol. 26, no. 5, pp. 357-369, 2010.

[35] B. Florenthal, "Applying uses and gratifications theory to students' LinkedIn usage," Young Consumers, vol. 16, no. 1, pp. 17-35, 2015.

[36] H. Chughtai and M. D. Myers, "Playing with IT: ethnographic Research on the Technological Practices of Young Professionals," presented at the Pacific Asia Conference on Information Systems, Chengdu, China, 2014.
[37] N. O. Ndubisi, P. Professor Rajan Nataraajan, I. M. AlJabri, M. S. Sohail, and N. O. Ndubisi, "Understanding the usage of global social networking sites by Arabs through the lens of uses and gratifications theory," Journal of Service Management, vol. 26, no. 4, pp. 662-680, 2015.

[38] A. Whiting and D. Williams, "Why people use social media: a uses and gratifications approach," Qualitative Market Research, vol. 16, no. 4, pp. 362-369(8), 2013.

[39] K. Y. Lin and H. P. Lu, "Why people use social networking sites: An empirical study integrating network externalities and motivation theory," Computers in Human Behavior, vol. 27, no. 3, pp. 1152-1161, 2011.

[40] U. M. Dholakia, R. P. Bagozzi, and L. K. Pearo, "A social influence model of consumer participation in network-and small-group-based virtual communities," International journal of research in marketing, vol. 21, no. 3, pp. 241-263, 2004.

[41] M. L. Weng and H. T. Ding, "E-shopping: An Analysis of the Uses and Gratifications Theory," Modern Applied Science, vol. 6, no. 5, 2012.

[42] W. W. Chin, "The partial least squares approach to structural equation modeling," Modern methods for business research, vol. 295, no. 2, pp. 295-336, 1998.

[43] S. Casey, "2016 Nielsen social media report."

[44] C. Fornell, "A second generation of multivariate analysis: Classification of methods and implications for marketing research," 1985.

[45] J. Henseler, C. M. Ringle, and M. Sarstedt, "A new criterion for assessing discriminant validity in variancebased structural equation modeling," Journal of the Academy of Marketing Science, vol. 43, no. 1, pp. 115-135, 2015.

[46] M. Wetzels, G. Odekerken-Schröder, and Van-Oppen, "Using PLS path modeling for assessing hierarchical construct models: Guidelines and empirical illustration," MIS Quarterly, vol. 33, no. 1, pp. 177-195, 2009.

[47] P. M. Leonardi, "Social Media, Knowledge Sharing, and Innovation: Toward a Theory of Communication Visibility," Information Systems Research, vol. 25, no. 4, pp. 796-816, 2014. 